\title{
ENGAJAMENTO NA PERSPECTIVA LINGUIISTICA SISTÊMICO-FUNCIONAL EM TRABALHOS DE CONCLUSÃO DE CURSO DE LETRAS
}

\section{ENGAGEMENT IN SYSTEMIC-FUNCTIONAL LINGUISTICS PERSPECTIVE ON UNDERGRADUATE STUDENT PAPERS OF LETTERS}

\section{Maria Otília Guimarães Ninin* Leila Barbara}

\section{RESUMO}

O estudo analisa, na perspectiva da teoria da avaliatividade, especificamente no subsistema de engajamento (MARTIN, 2000; WHITE, 2004 [2002]; MARTIN e WHITE, 2005), como estudantes de graduação em Letras apresentam vozes teóricas em Trabalhos de Conclusão de Curso (TCC), revelando preferência por expansão dialógica do tipo ponderação (probabilidade) e atribuição (reconhecimento). Resultados evidenciam pequena responsabilidade da voz autoral.

Palavras-chave: engajamento; expansão dialógica; contração dialógica.

\section{ABSTRACT}

Based on the Appraisal System, more specifically on the Engagement subsystem (MARTIN, 2000; WHITE, 2002/2004; MARTIN and WHITE, 2005), this study analyzes the way undergraduate students of Letras present theoretical voices in their B.A. final works, showing preference for dialogic expansion - entertainment (probability) and attribution (acknowledgement). Results evidence a low degree of responsibility of the authorial voice. Keywords: engagement; dialogic expansion; dialogic contraction.

\section{INTRODUÇÃO}

Tendo em vista que a escrita acadêmica constitui-se em espaço de negociação e de construção de posicionamentos e avaliação para os membros da comunidade acadêmica, e que a produção textual de estudantes de graduação pressupõe uma

* PUC-SP-COGEAE CNPq / UNIP-SP, São Paulo (SP), Brasil. otilianinin@terra.com.br; PUC-SP / CNPq, São Paulo (SP), Brasil. lbarbara@uol.com.br 
importante transição nos modos de escrita vivenciados no ensino básico, por exigir dos autores capacidades analíticas e maior compreensão de análise crítica e argumentação, este artigo tem como objetivo analisar e discutir as características do discurso de graduandos em Letras na seção teórica de trabalhos de conclusão de curso (TCCs), propiciando um espaço de reflexão sobre as necessidades no ensino desse tipo de escrita.

Conquanto espere-se que os estudantes recorram a autores relevantes ao assunto tratado, marcando sua maior ou menor concordância com os trabalhos citados ou com seus autores, a experiência com orientação de TCCs tem mostrado que, apesar de terem passado de 3 a 4 anos de graduação em contato com textos científicos, os graduandos tendem a distanciar-se desse tipo de discurso, organizando seus textos como uma coletânea - "colcha de retalhos" - de citações de vozes de autoridades. Embora tenham tido contato frequente com textos científicos nas diferentes disciplinas do curso, não demonstram compreensão de sua organização linguístico-discursiva. Justifica-se, pois, um trabalho de investigação em busca de compreender como são feitas as citações de autores usados como referência, as manifestações de concordância ou não do autor estudante sobre elas e a emissão de suas próprias considerações.

Com base em diferentes abordagens teóricas, aspectos como nomeação do sujeito autor, percurso de autoria, apropriação das características dos gêneros acadêmicos e desenvolvimento de propostas para o ensino da escrita têm sido contemplados nas pesquisas sobre gêneros acadêmicos de importantes estudiosos, como Bazerman (1988), Bazerman e Prior (2004), Swales (1990), Martin (1993), Martin e Rose (2003), Hood (2004, 2010), Motta-Roth (2001, 2002, 2006, 2007), Hendges (2002), Araujo (2002), Machado (2002), Borges e Moreira (2004), Machado et al. (2005), Figueiredo e Bonini (2006), Oliveira (2008), Botelho (2009), Motta-Roth e Hendges (2010), Motta-Roth e Lovato (2011), Santos e Carmo (2011).

Neste artigo, ancorado na teoria sistêmico-funcional (HALLIDAY, 1985, 1994), mais especificamente, no sistema de Avaliatividade ${ }^{1}$ e seu subsistema de Engajamento (WHITE, 2004 [2002]; MARTIN e WHITE, 2005), buscase caracterizar e discutir a dialogicidade presente nos textos produzidos por graduandos em Letras, aspecto indicativo não somente da apropriação do gênero textual em questão, mas também do envolvimento do estudante/autor perante as

\footnotetext{
1 Dentre as várias traduções para termos utilizados na LSF em português, este trabalho utiliza as disponíveis em <http://www2.lael.pucsp.br/ tony/sistemica/termos/db.cgi? db=default\&uid=def ault\&view_records $=1 \& \mathrm{ID}={ }^{*} \& \mathrm{sb}=2>$ Acesso em: 15.out.2011.
} 
vozes evocadas em seu texto. São analisados os padrões utilizados em um corpus de trabalhos recolhidos de sites livres da internet, de diferentes universidades, a fim de contribuir para a orientação na elaboração de TCCs e no ensino do texto científico.

$\mathrm{Na}$ primeira seção do artigo são apresentadas contribuições teóricas relacionadas ao subsistema de engajamento, dando especial atenção aos recursos de expansão dialógica mais recorrentes no corpus pesquisado. A seção 2 dedica-se às características metodológicas: descrição do corpus e procedimentos de análise. A seção 3, focalizando expansão e contração dialógicas, destina-se à discussão de excertos selecionados do corpus pesquisado, com destaque para os padrões de recursos de engajamento encontrados. Nas considerações finais, uma síntese dos resultados é apresentada, sugerindo novas reflexões sobre caminhos para o ensino da escrita acadêmica junto aos graduandos.

\section{FUNDAMENTOS TEÓRICOS: O ENGAJAMENTO NO DISCURSO}

Na perspectiva da Teoria da Avaliatividade, subárea da LSF, apresentada inicialmente por Eggins e Slade (1997), por Martin (2000, 2004) com base na metafunção interpessoal e desenvolvida posteriormente por Martin e White ${ }^{2}$ (2005), três tipos de recursos estão estreitamente relacionados - Atitude, Engajamento e Gradação -, possibilitando ao falante/escritor expressar afeto, julgamento, apreciação, aumentar ou diminuir o grau de avaliatividade e, ainda, expressar posicionamentos e opiniões. Dentre eles, este estudo concentra-se no subsistema de Engajamento, que se ocupa dos modos como a voz textual posicionase em relação a outras vozes presentes no texto, procurando caracterizar diferentes perspectivas intersubjetivas disponíveis, ou seja, permitindo caracterizar o modo de adesão ou não do falante/escritor em relação às proposições no texto.

Martin e White (2005, p.93-95), explicitando aspectos relacionados ao subsistema de Engajamento, apontam como princípios de sua organização: (1) o grau a partir do qual falantes/escritores reconhecem vozes anteriores e o modo como se engajam nelas; (2) o aspecto de antecipação do texto, isto é, os sinais que falantes/escritores fornecem sobre como ouvintes/leitores responderão à proposição e ao valor posicional apresentados nos textos.

2 Peter White, em The Appraisal Website: Homepage (Disponível em: < http://www.grammatics.com/ appraisal/> Acesso em: 15.nov.2011), apresenta a teoria da avaliatividade como um modo de olhar para a linguagem utilizada para avaliar, adotar posturas, construir personas textuais e gerir posicionamentos e relacionamentos interpessoais. 
Tais princípios, articulados diretamente aos conceitos bakhtinianos de dialogismo e heteroglossia (MARTIN e WHITE, 2005, p.93), organizam o subsistema de Engajamento, considerando-se que toda comunicação verbal, falada ou escrita, é influenciada diretamente por algo já dito ou falado, antecipando ou orientando respostas de ouvintes/leitores. Relações estabelecidas entre falante/ escritor e ouvinte/leitor, como diz Brait (1997/2001, p.98), não estão pautadas somente em um discurso harmonioso e simétrico, mas em contradições situadas sócio-historicamente, que orientam e instauram os eventos discursivos.

Recorrendo a diferentes enunciados, apresentando a voz textual a partir de múltiplas perspectivas individuais e sociais, o subsistema de Engajamento responsabiliza-se, portanto, por posicionamentos assumidos pela voz textual, dialógicos e heteroglóssicos, para possibilitar responsividade por parte do ouvinte/ leitor.

White (2003) e Martin e White (2005), ao discutirem o subsistema de Engajamento, pontuam que todo texto é heteroglóssico, quando recorre aos recursos que permitem espaço para alternativas dialógicas; ou é monoglóssico, quando esses espaços não são abertos no texto. Olhando o texto como um conjunto de orações, "é possível fazer asserções categóricas que não permitem o questionamento ou que não dão margem à dialogia" (VIAN JR., 2011, p.35), o que implicaria a monoglossia. No entanto, na perspectiva semântico-discursiva, as asserções, vistas como um conjunto situado contextualmente, tornam-se um todo heteroglóssico (p.36).

Em outras palavras, não é possível conhecer o envolvimento do autor com as proposições apresentadas no texto quando se analisa isoladamente as orações. É, pois, no conjunto delas, seja em um parágrafo ou enquanto durar um dado tema na trama textual, que se pode discutir a heteroglossia ou a monoglossia do texto.

Com base em White (2004 [2002]) e Martin e White (2005), o subsistema de Engajamento é apresentado a seguir: 


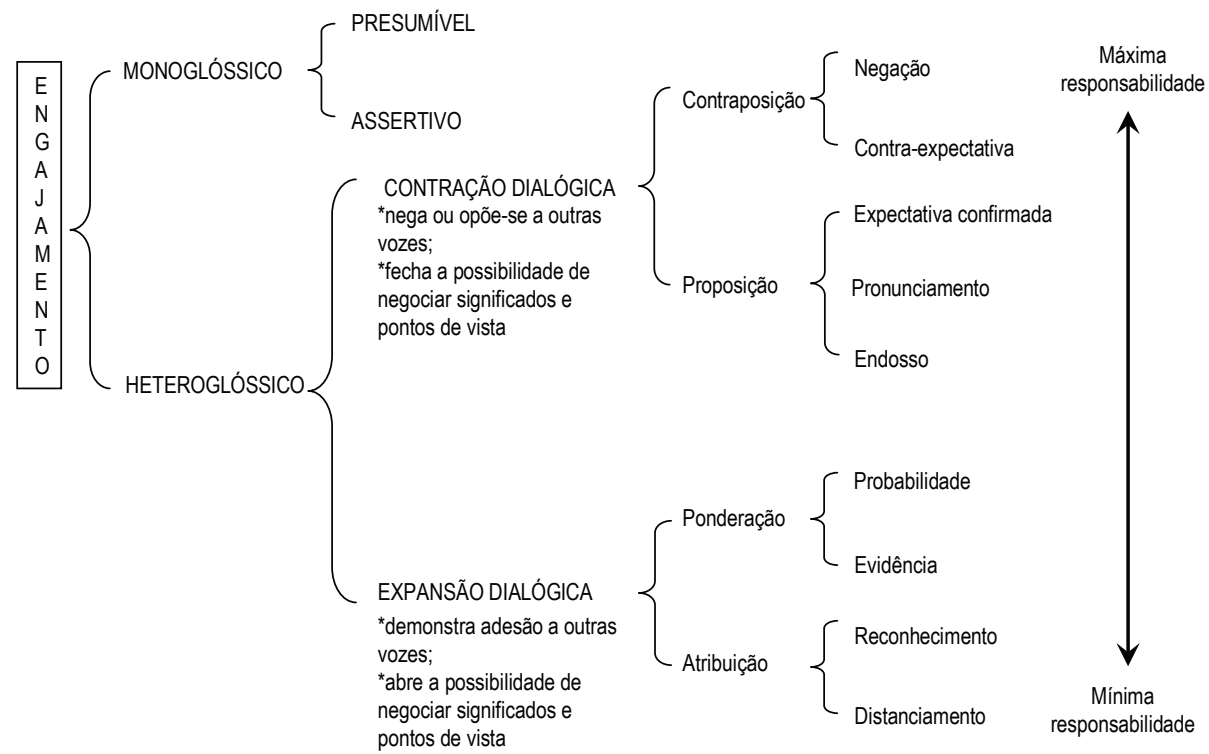

Figura 1. Subsistema de Engajamento - baseado em Martin e White $(2005$, p.122, 134) e White (2011, p. 1)

$\mathrm{Na}$ perspectiva monoglóssica, o falante/escritor tem a possibilidade de enunciar algo que está pressuposto ou que não permite questionamento. Exemplificando ${ }^{3}$ :

(1) "Uma vez realizada a coleta de dados orais, os participantes decidiram eliminar os textos escritos" (tcc11)

Em (1), o modo declarativo assertivo - decidiram eliminar - permite inferir que o que está pressuposto não está em discussão, contribuindo, assim, para a monoglossia do texto.

(2) "As discussões influenciam os participantes da pesquisa" (tcc9)

Nesse exemplo, o enunciado declarativo, apresentado como verdadeiro, elimina possibilidades de presença de outros enunciados alternativos ou que o contradizem.

3 Muitos exemplos, selecionados do corpus analisado, por terem sido produzidos por estudantes de graduação, podem apresentar inconsistências. 
Ignorando a diversidade de outros enunciados, os monoglóssicos não possibilitam o reconhecimento de alternativas dialógicas. Proposições, declaradas de modo absoluto, são tratadas como certas, indiscutíveis, ou como não-problemáticas, baseadas em conhecimento consensual, em fatos, eventos conhecidos e aceitos pela comunidade discursiva. No discurso científico, esse tipo de afirmação corresponde a conhecimentos já consagrados, consolidados e estabelecidos.

Já em relação à heteroglossia, há um reconhecimento, de alguma forma, da diversidade associada aos enunciados. Os recursos apontados por White (2011), sinalizadores de algum compromisso com posições alternativas, caminham em duas direções: uma, a contração dialógica, corresponde a proposições que restringem, desafiam ou dispersam alternativas e diversidade de vozes; outra, a expansão dialógica, trata de proposições que ampliam o espaço dialógico, permitindo a entrada de posições alternativas.

Pelo exemplo (3), é possível entender no que pode resultar recorrerse à contração dialógica, especificamente à negação, recurso indicativo de máxima responsabilidade enunciativa do falante/escritor.

(3) "Afinal, não há texto que não se constitua de outros textos, e o dito é sempre perpassado por outros dizeres" (tcc5)

Invocando uma posição contrária - a de que algum texto não se constitui de outros textos - e se posicionando como uma resposta em relação a essa posição, a negação caracteriza posicionamento dialógico de contração, tendo a responsabilidade da voz autoral fortalecida, ainda, pelo uso do advérbio afinal, que, no papel de operador argumentativo, sinaliza maior envolvimento do falante/ escritor com a posição assumida no texto, produzindo um efeito de fechamento de sentido.

Por outro lado, recorrendo ao recurso da expansão dialógica, especificamente ao distanciamento, o falante/escritor assume mínima responsabilidade enunciativa, deixando explicitada sua posição de discordância ou de não envolvimento com o posicionamento presente no texto. A responsabilidade cabe à voz externa trazida ao texto. Exemplificando:

(4) "Por outro lado, com base na teoria de Sökmen, a autora Souza (2007) alega que alguém que está aprendendo uma língua ou conhecendo palavras novas de uma língua $(. . .)^{\prime \prime}(\operatorname{tcc} 13)$. 
Em certo sentido, o distanciamento marca a rejeição da voz autoral em relação ao que é dito, neutralizando sua responsabilidade enunciativa. $\mathrm{O}$ verbo alegar, cuja carga semântica indica a apresentação de argumentos em defesa de algo, distancia a voz autoral do posicionamento presente no texto.

Recursos como negação, contra expectativa, expectativa confirmada e pronunciamento caracterizam maior responsabilidade assumida pelo falante/escritor. Já recursos como endosso, probabilidade e evidência caracterizam uma responsabilidade assumida parcialmente pelo falante/escritor, sendo sua voz uma dentre outras presentes no enunciado, enquanto os recursos de reconbecimento e distanciamento mostram a responsabilidade atribuída a uma voz externa. Esses recursos serão apresentados na seção de discussão.

\section{PROCEDIMENTOS METODOLÓGICOS}

O corpus de estudo, constituído de 20 monografias de conclusão de curso de letras (TCCs) retiradas de bibliotecas virtuais de diferentes universidades, gravadas em formato txt, submetidas ao programa computacional WordSmith Tools 5.0 (WST) (Scott, 2009), inclui temas como Ensino de Língua Portuguesa / Inglesa, Sociolinguística, Normas Linguísticas e outros.

Quadro 1. Características do Corpus

\begin{tabular}{|l|r|}
\hline$N^{\circ}$ de textos & 20 \\
\hline Tamanho do arquivo & 418279 \\
\hline Palavras usadas na lista & 64625 \\
\hline Palavras diferentes & 8503 \\
\hline Sentenças & 2285 \\
\hline
\end{tabular}

As seções teóricas dos textos do corpus foram submetidas ao aplicativo Wordlist, do WST, observando-se a lista de palavras do conjunto de textos por ordem decrescente de frequência, selecionadas as mais recorrentes e, posteriormente, agrupadas conforme o tipo de engajamento, com vistas a caracterizar o discurso do grupo. Destacadas as escolhas linguísticas características dos recursos de Engajamento, optou-se pelo uso do aplicativo Concord, do WST, que apresenta lista das ocorrências das escolhas linguísticas características dos recursos de engajamento, acompanhadas do texto ao seu redor. A partir daí, foram computadas as ocorrências para discussão. 


\section{ANALISANDO E DISCUTINDO AS VOZES NOS TEXTOS}

Esta seção discute os tipos de engajamento, a partir dos mais recorrentes, quantificados e sumarizados no quadro abaixo.

Quadro 2. Recursos Heteroglóssicos de Engajamento

\begin{tabular}{|c|c|c|c|c|c|}
\hline $\begin{array}{c}\text { Tipo de } \\
\text { Engajamento }\end{array}$ & Categoria & Recurso & No. & $\begin{array}{l}\text { Percentual em } \\
\text { relação ao total } \\
\text { de cada tipo } \\
\text { (CD e ED) }\end{array}$ & $\begin{array}{l}\text { Percentual em } \\
\text { relação ao total } \\
\text { de recursos }\end{array}$ \\
\hline \multirow{6}{*}{$\begin{array}{l}\text { Contração } \\
\text { Dialógica } \\
\text { (CD) }\end{array}$} & \multirow[b]{2}{*}{ Contraposição } & Negação & 19 & 9,6 & 2,1 \\
\hline & & $\begin{array}{c}\text { Contra- } \\
\text { expectativa }\end{array}$ & 53 & 26,6 & 6,0 \\
\hline & \multirow{3}{*}{ Proposição } & $\begin{array}{l}\text { Expectativa } \\
\text { confirmada }\end{array}$ & 93 & 46,7 & 10,5 \\
\hline & & Pronunciamento & 34 & 17,1 & 3,8 \\
\hline & & Endosso & 0 & 0,0 & 0,0 \\
\hline & & Total parcial & 199 & 100,0 & 22,4 \\
\hline \multirow{6}{*}{$\begin{array}{c}\text { Expansão } \\
\text { Dialógica } \\
\text { (ED) }\end{array}$} & \multirow[b]{2}{*}{ Ponderação } & Probabilidade & 380 & 55,0 & 42,7 \\
\hline & & Evidência & 18 & 2,6 & 2,0 \\
\hline & \multirow[b]{2}{*}{ Atribuição } & Reconhecimento & 293 & 42,4 & 32,9 \\
\hline & & Distanciamento & 0 & 0,0 & 0,0 \\
\hline & & Total parcial & 691 & 100,0 & 77,6 \\
\hline & & Total geral & 890 & & 100,0 \\
\hline
\end{tabular}

Em primeiro lugar, pode-se observar substancial presença da expansão dialógica $-77,6 \%$, em oposição a $22,4 \%$ de contração dialógica, o que pode ser explicado levando-se em conta o tipo de autor dos textos analisados - o aluno de graduação, considerado iniciante na escrita acadêmica. $\mathrm{O}$ uso da expansão dialógica sinaliza pouca responsabilidade assumida pela voz autoral sobre o que é apresentado no texto, abrindo possibilidades de negociação dos significados. A responsabilidade é ora atribuída às vozes externas - evidenciada no alto uso do recurso de Atribuição por Reconhecimento; ora parcialmente assumida pelo falante/escritor - destacada no uso da Ponderação por Probabilidade. Sendo os mais recorrentes, esses recursos equivalem a $75 \%$ do total de Engajamento encontrado no corpus.

A alta presença do recurso de contração dialógica por Proposição Expectativa Confirmada - é também característica do texto produzido por um autor iniciante no texto acadêmico, ao apresentar proposições - muitas vezes com efeito retórico - que visam obter a concordância do leitor. 


\subsection{Recursos de contração dialógica}

Uma vez considerado que a contração dialógica permite ao falante/escritor expressar relações de intersubjetividade restritivas frente às vozes presentes no texto, desencorajando a negociação de significados (MARTIN e WHITE, 2005), maximizando ou deixando mais evidente a responsabilidade enunciativa do falante/ escritor, observou-se que recursos dessa natureza são utilizados em menor escala por graduandos. Nessa direção, a experiência com orientação de TCCs tem mostrado o receio dos alunos em relação ao modo de usar vozes teóricas: se ausentes, o discurso se caracterizaria como senso comum; se em excesso, como plágio.

Embora recursos de contração dialógica sejam pouco frequentes, (5) é exemplo ${ }^{4}$ de contraposição: contra-expectativa seguida de negação, reforçada pelo uso da oração coordenada iniciada por nem, que adiciona segmento negativo ao segmento anterior.

(5) Assim, embora (contra-expectativa) as habilidades linguísticas para pensar criticamente sejam fundamentais, não bá como (negação) prescrever caminhos lineares para esse pensar, nem (negação) tampouco considerar que (...) (tcc7)

Conquanto estejam presentes no enunciado duas vozes em contraposição, e uma posição alternativa seja reconhecida (embora as babilidades linguísticas para pensar criticamente sejam fundamentais), esta não é apresentada como possível, mas sim como uma verdade incompatível em relação à posição assumida pelas orações negativas (não bá como prescrever caminhos lineares para esse pensar, nem tampouco considerar que...). É possível inferir que a contra-expectativa foi utilizada somente para apresentar uma posição a ser rejeitada na negociação de significados.

(6) Esse modo de aproximação requer que não se tome (negação) cada enunciado em separado, mas (contra-expectativa) se trabalhe na tessitura do movimento interlocutivo. (tcc17)

Já em (6), a contra-expetativa (se trabalbe na tessitura do movimento interlocutivo) contraria o que foi negado (não se tome cada enunciado em separado), parecendo indicar a presença de um ponto de vista que já surge para ser rejeitado.

Recursos dessa natureza, que marcam a responsabilidade da voz autoral sobre os pontos de vista apresentados no texto, foram pouco utilizados pelos estudantes autores na elaboração dos textos analisados.

4 Vale lembrar: os exemplos, por terem sido produzidos por estudantes de graduação, podem apresentar inconsistências. 
Exemplos semelhantes são (7) e (8):

(7) (...) talvez a total reformulação dos materiais didáticos, com novas propostas, não de (negação) suportes e plataformas apenas, mas de (contra-expectativa) novos gêneros com fins didáticos - multimodais, multissemióticos, multiculturais, digitais, online - que possam dar conta das demandas atuais (...) (tcc3)

(8) É, portanto, nessa esfera de interação que minha pesquisa se insere: $n a \tilde{o}$ (negação) na perspectiva da existência de um sujeito não assujeitado, nem (negação) de um sujeito que tem plena consciência de seu dizer, mas (contra-expectativa) de um sujeito atuante na esfera da interação verbal. (tcc19)

Em (9), a seguir, o aluno-autor utiliza contração dialógica do tipo contraposição por contra-expectativa associada à expansão dialógica ponderação por probabilidade, enfraquecendo o primeiro ponto de vista.

(9) Apesar de (contra-expectativa) o leitor continuar sendo um mero decodificador, podemos notar que (probabilidade) há uma diferença entre esse modelo e o exposto acima: o conhecimento prévio do leitor na concepção descendente de leitura é valorizado. (tcc11)

Em (10) e (11) o aluno-autor utiliza recursos de contração dialógica do tipo proposição - expectativa confirmada e pronunciamento, respectivamente.

(10) É claro que (expectativa confirmada) há distinções bastante claras quanto aos dois gêneros, mas (...) um trabalho publicado numa revista científica não tem, obviamente, a mesma classificação (...) (tcc12)

(11) (...) se tomarmos essa imagem como elemento para construção de um discurso, não bá dúvida (pronunciamento) de que são signos dotados de motivação (...) (tcc20)

Partindo de enunciado retórico revelador da responsabilidade do autor sobre o que é dito, a expectativa confirmada tem o propósito de ganhar a concordância do leitor. Também pouco utilizado no corpus, esse recurso recorre ainda aos advérbios modalizadores epistêmicos asseverativos afirmativos ou negativos, apresentados pelo falante/escritor para evidenciar algo (certamente, obviamente, naturalmente), como em (10).

Em (11), o pronunciamento se caracteriza pelo uso do adjunto modal (não bá dúvida), para enfatizar a posição discursiva do autor e, de certa forma, desencorajar a discordância do interlocutor. 
Já no exemplo (12), a seguir, por meio do endosso, o aluno-autor recorre ao verbo factivo confirmar para atribuir determinada posição discursiva a uma voz externa, porém, reconhecendo-a, tomando-a para si.

(12) Acreditamos (endosso) que muitas piadas de Joãozinho podem confirmar a tese proposta por Freud, Bergson e Propp - a piada pode servir a propósitos hostis, é criada para humilhar. (tcc15)

O uso do endosso possibilita à voz textual transformar em heteroglóssico um enunciado que, em primeira instância, seria monoglóssico (proposição asseverativa - a piada pode servir a propósitos hostis, é criada para bumilhar) se o considerássemos uma oração independente.

\subsection{Recursos de expansão dialógica}

$\mathrm{Na}$ perspectiva da expansão dialógica, o falante/escritor deixa transparecer a ideia de que seu posicionamento em relação a uma dada proposição presente no texto está aberto, sendo sua voz apenas uma dentre tantas possibilidades para se atribuir sentido àquilo que está em jogo.

Exemplos a seguir evidenciam recursos de ponderação por probabilidade, o tipo mais utilizado pelos alunos autores, quando recorrem aos verbos auxiliares modais e a adjuntos modalizadores com função de atenuação, como, por exemplo: verbos dever, poder, querer e suas inflexões (deveria, poderia, gostaria, etc.) ou a advérbios como provavelmente, geralmente, ocasionalmente. A tabela 1 mostra os recursos de probabilidade encontrados no corpus:

Tabela 1. Recursos de ponderação do tipo probabilidade

\begin{tabular}{|c|c|}
\hline Escolha lexical & Frequência \\
\hline talvez & 14 \\
\hline formas dedever & 67 \\
\hline formas de poder & 276 \\
\hline provavelmente & 5 \\
\hline possível & 18 \\
\hline TOTAL & 380 \\
\hline
\end{tabular}

(13) No contexto do filme Narradores de Javé, é possível (probabilidade) observar como ficção e realidade dialogam (...) (tcc14)

(14) Talvez (probabilidade) por esse motivo, a autora argumenta [sic] que existe certa displicência com relação às exigências (...) (tcc11) 
(15) Portanto, esse esquecimento é condição para que o sujeito possa significar, possa (probabilidade) produzir efeitos de sentido. (tcc17)

Em cada situação está disponível ao ouvinte/leitor a possibilidade de interpretar os enunciados como um sinal de que o conhecimento do falante/escritor sobre o foco da discussão é, de certa forma, limitado e não suficiente para que formule uma proposição categórica (MARTIN e WHITE, 2005), expandindo o potencial dialógico.

Verbos que denotam atitude ou opinião, como acho, penso, creio, acredito, parece, caracterizam o recurso de ponderação do tipo evidência, como em (16), cuja realização se dá pelo uso de um daqueles processos mentais indicativos de atitude proposicional (acreditamos) e pela presença de modal, no caso, um adjetivo (possível).

(16) (...) há um ser/estar-entre-línguas-culturas em um único país, de (aparentemente) uma única língua. E pensando nisso, acreditamos ser possível observar, em meio às "brechas" da linguagem, dentro da materialidade discursiva do aluno-migrante, como sua identidade (...) (tcc19)

E mais: o recurso de ponderação (acreditar ser possível), reforçado pelo advérbio de modo aparentemente, marcando incerteza, corresponde à formulação de uma hipótese indicativa, portanto, de responsabilidade apenas parcial, hipotética de verdade em relação aoque é dito.

No exemplo (17), a seguir, a articulação entre os recursos ponderação por evidência, negação e contra-expectativa indica uma aparente abertura para a negociação dos significados:

(17) (...) as mídias, manipulam tanto quanto manipulam a si mesmas, o que nos leva a acreditar que não são desprovidas de persuasão, uma vez que elas estão ao alcance de atingir o maior número de pessoas possível. (tcc6)

Ao mesmo tempo em que a responsabilidade do falante/escritor (nos leva a acreditar) é minimizada, subordina-se ao verbo uma oração negativa cuja credibilidade fica abalada pela própria presença do recurso de probabilidade e, também, pela oração que se contrapõe (uma vez que...).

Situação semelhante ocorre no exemplo (18), no qual três elementos articulados indicam o engajamento:

(18) Porém, o Guia parece privilegiar somente esse aspecto, não mencionando ou referindo-se de maneira vaga a outros elementos do projeto gráfico-editorial. (tcc13) 
Porém, operador argumentativo que orienta a argumentação contrariando o que foi introduzido anteriormente, perde a força argumentativa ao aparecer articulado a parece, verbo modal de baixo grau de engajamento, que, por sua vez, articula-se a uma oração negativa categórica. A construção frasal, nesse caso, tem a aparência de expansão dialógica; no entanto, a ambiguidade causada pela articulação entre porém e parece pode indicar maior valor de verdade à oração negativa.

Escolhas indicativas de expansão dialógica do tipo atribuição por reconbecimento, apresentadas na tabela 2, trazem ao texto vozes externas recontextualizadas, sem deixar claro um real envolvimento e consideração do aluno autor por essas vozes. Proposições adentram ao texto apenas pela sinalização da voz autoral, por meio de citações, relatos, verbos do dizer, mentais, além de circunstâncias de ângulo e nominalizações dos processos.

Tabela 2. Recursos de atribuição do tipo reconhecimento

\begin{tabular}{|c|c|}
\hline $\begin{array}{c}\text { Escolha } \\
\text { lexicogramatical }\end{array}$ & Quant. \\
\hline segundo & 92 \\
\hline de acordo com & 46 \\
\hline afirma & 51 \\
\hline diz & 22 \\
\hline conforme & 21 \\
\hline conclui & 7 \\
\hline argumenta & 6 \\
\hline considera & 16 \\
\hline aponta & 12 \\
\hline mostra & 10 \\
\hline sugere & 4 \\
\hline lembra & 4 \\
\hline enfatiza & 2 \\
\hline TOTAL & 293 \\
\hline
\end{tabular}

Ocorre com grande frequência no corpus ( $2^{\text {a }}$ maior) o reconbecimento, sem que o aluno autor mostre seu envolvimento com a proposição apresentada, mas sim preocupando-se com a apresentação da voz de autoridade, eximindo-se da responsabilidade de articular os diferentes posicionamentos aos quais recorre. $\mathrm{O}$ exemplo a seguir, de reconbecimento, é o único no corpus que mostra uma negociação de significados na qual a voz autoral assume responsabilidade.

(19) Segundo Preti (2004, p.15), o que prejudica os falantes da norma não-padrão é o desconhecimento de estratégias linguísticas de variação (...) Bagno (2001, p.25) faz um contraponto ao que Preti mencionou, ao afirmar que "todas as variedades de uma língua têm recursos linguísticos suficientes para desempenhar sua função de veículo de comunicação, de expressão e de interação entre seres humanos". (tcc8) 
Duas vozes de autoridade - Preti, por meio da circunstância de ângulo indicativa de reconbecimento e Bagno, por meio do distanciamento - são apresentadas para trazer à tona um aspecto de discordância, o que confere certa responsabilidade ao autor do texto. Quanto à utilização do verbo afirmar, um dos mais recorrentes no corpus, Barbara e Macedo (2011), ao discutirem os processos verbais em artigos acadêmicos, destacam o fato de esse processo não pressupor "necessariamente alguém a quem a mensagem seja dirigida, devido à sua natureza categórica, não negociadora" (p.216). Ao utilizar esse processo na apresentação da voz de Bagno, o aluno autor parece ignorar a transitoriedade da ciência, atribuindo à voz externa uma proposição inquestionável.

Em (20), o aluno-autor minimiza sua responsabilidade enunciativa depositada, por força do afirmar, na voz externa, modificando-o pelo recurso de ponderação por evidência, indicando, portanto, sua não convicção em relação a uma dada proposição que sem ele (parece) poderia ser entendida como indiscutível.

(20) (...) televisão, jornal, revistas, peças publicitárias - parecem afirmar em nosso tempo o estatuto da mídia não só como vinculadora, mas também como produtora de saberes e formas especializadas de comunicar e de produzir sujeitos (...) (tcc17)

Já em relação às circunstâncias de ângulo, como em (21) a (24), são frequentemente utilizadas:

(21) Nessa ótica, alguns teóricos acreditam, segundo as palavras de Lima (2004, p.178) que a alternância de línguas: é uma forma de fala confusa, uma mescla agramatical de línguas. (tcc4)

(22) No ponto de vista de Carrascoza (1999), tais idéias consistem numa forma de raciocínio que mescla e amalgama idéias a outras idéias (...) (tcc10)

(23) Segundo Orlandi, em condições de produção em sentido estrito (ato da enunciação) e em sentido amplo (contexto sóciohistórico-ideológico). (tcc2)

(24) A partir daí, Bergson estabelece uma série de "leis" que, segundo ele, regulamentam o cômico. (tcc16)

Em (21), a responsabilidade do autor é neutralizada ainda mais pela atribuição de uma dada proposição a uma voz externa (Lima), acompanhada da expressão alguns teóricos acreditam, caracterizando distanciamento. Embora o aluno autor reconheça 
a voz de Lima, o léxico alguns enfraquece a autoridade tanto dos teóricos quanto do próprio Lima, revelando ao leitor uma credibilidade abalada.

Circunstâncias de ângulo indicativas de reconbecimento, como em (22) e (23), utilizadas apenas para destacar a autoridade da ciência pela apresentação de posicionamentos externos, sem que o aluno autor os utilize na tessitura de sua voz às já presentes no texto, dificulta, como dizem Motta-Roth e Lovato (2011, p.261), "uma clara identificação da distância retórica estabelecida entre a voz autoral e o conteúdo da proposição projetada".

Em (24), o recurso de reconbecimento em relação à voz de Bérgson, fortalecido pelo uso do operador argumentativo a partir dá́, busca a adesão do leitor a partir de algo já concluído anteriormente.

No exemplo seguinte, o recurso de engajamento utilizado denota o distanciamento da voz autoral:

(25) É interessante perceber também que (...) o autor só tem participação ativa no início, com o envio dos originais. Como Roberta relatou, mesmo exercícios e atividades do LDP podem vir a ser produzidas por terceiros, quando são sugestões do editor que o autor alega não ter tempo ou mesmo vontade de elaborar. (tcc18)

A proposição é apresentada como questionável, potencialmente aberta a outras posições alternativas. Processos utilizados para reconbecimento, como mostrar, demonstrar, pressupõem maior confiabilidade em relação a proposições apresentadas, enquanto alegar, sugerir indicam o distanciamento da voz autoral em relação à credibilidade das proposições (WHITE, 2003). No exemplo, a oração podem vir a ser produzidas por terceiros, indicativa de modalidade epistêmica (menor grau de certeza), evidencia o distanciamento.

Alguns processos indicativos de ponderação por evidência podem também indicar atribuição por reconbecimento. Identifica-se corresponder a um ou outro recurso pela forma como o falante/escritor mostra seu envolvimento: se ponderação por evidência (26), o falante/escritor é quem apresenta uma dada proposição; se atribuição por reconbecimento, a voz autoral recorre a uma voz externa (27):

(26) E pensando nisso, acreditamos ${ }^{5}$ ser possível observar, em meio às "brechas" da linguagem, dentro da materialidade discursiva do aluno-migrante, como sua identidade é permeada por tais conflitos e como a escola lida com as variações linguístico-culturais. (tcc9)

\footnotetext{
$5 \mathrm{O}$ verbo aparece na $1^{\text {a }}$ pessoa do plural pelo fato de o TCC ter sido desenvolvido por uma dupla
} de alunos. 
(27) Uma vez que todos os textos se manifestam em gêneros textuais, o autor [Marcuschi] acredita que os gêneros são importantes para a produção e compreensão de textos. Essa é a idéia básica que se vê no centro dos PCN. (tcc1)

Em síntese, os exemplos apresentados revelam o engajamento do alunoautor ao produzir a seção de revisão da literatura de seu trabalho de conclusão de curso. A ênfase, como pôde ser vista, está nos recursos que caracterizam uma responsabilidade mínima da voz autoral. Ao utilizar esse tipo de recurso e também ao apresentar tópicos discursivos que concordam entre si, distanciando-se de pontos de vista alternativos e conflitantes, o aluno-autor sente-se desobrigado de apresentar sua voz como articuladora dos conceitos tratados. Nesse sentido, a expansão dialógica pode ser vista como uma pseudo expansão, sendo o destaque dado às vozes teóricas de fontes externas ao texto, como marcas de autoridade.

\section{CONSIDERAÇÕES FINAIS}

O artigo apresentou uma discussão sobre os recursos de Engajamento (MARTIN e WHITE, 2005), subsistema da Teoria da Avaliatividade e subjacente à metafunção interpessoal (HALLIDAY, 1994). Engajamento, nessa perspectiva, caracteriza-se como um modelo sistemático para observar as realizações linguísticas em posicionamentos intersubjetivos assumidos por falantes/escritores.

A pesquisa descrita teve como objetivo principal discutir o engajamento em textos científicos produzidos em contexto de graduação em Letras, oferecendo contribuições a professores orientadores de trabalhos do gênero acadêmico. Resultados indicam a predominância dos recursos de engajamento dos tipos ponderação por probabilidade e atribuição por reconbecimento.

Observou-se que o aluno da graduação marca uma posição de pouca responsabilidade em relação às proposições convidadas ao texto, contrariando o que se tem como meta no ensino superior - o desenvolvimento e a autonomia intelectual do aluno. Embora este tenha contato contínuo, ao longo da graduação, com a escrita acadêmica e leia textos científicos, não demonstra ter internalizado suas características linguístico-discursivas.

Os resultados encontrados são referência para a continuidade deste estudo, uma vez que a presença marcante de ponderação por probabilidade e atribuição por reconbecimento permite investigar e analisar como o aluno traz para seu texto a voz de autoridade - os teóricos estudados - e como articula essa voz à sua, fato que se relaciona diretamente aos resultados de pesquisas já realizadas sobre a 
escrita acadêmica, como de Motta-Roth e Lovato (2011), que indicam também a predominância do recurso de expansão dialógica; e de Pedrosa et al. (2008) que, ao discutirem a polifonização ou monofonização do discurso acadêmico, destacam o fato de o dialogismo tender à monologização, uma vez que as vozes são evocadas para defender um ponto de vista e não para polemizar sobre esse ponto de vista.

No corpus estudado, embora a expansão dialógica abra possibilidades para a negociação de significados, acaba sendo utilizada para destacar o discurso de autoridade, seja pela ausência de posicionamentos ou pela ausência de vozes que trazem posições opostas para a negociação, obscurecendo, dessa forma, a voz autoral. A pesquisa pode ser considerada, portanto, como ponto de partida para um trabalho mais aprimorado de ampliação da discussão sobre como organizar estratégias de ensino que permitam ao aluno-autor da graduação compreender o papel dos elementos textuais e da estrutura retórica na organização do texto científico, visando à produção de textos legitimados pela comunidade acadêmica.

\section{REFERÊNCIAS BIBLIOGRÁFICAS}

ARAÚJO, A.D. (2002). Uma análise da polifonia discursiva em resenhas críticas acadêmicas. In: MEURER, José Luiz; MOTTA-ROTH, Désirée. (orgs.) Gêneros textuais. Bauru, SP: EDUSC. (pp.141-158)

BAKHTIN, M. (1929/1999). Marxismo e Filosofia da Linguagem. São Paulo: Hucitec.

BALOCCO, A.E. (2011). O sistema do engajamento aplicado a espaços opinativos na mídia escrita. In: VIAN JR, O.; SOUZA, A.A. de; ALMEIDA, F.S.D.P. (orgs.) Estudos sistêmico-funcionais com base no Sistema de Avaliatividade. São Carlos: Pedro \& João Editores. (pp.41-52)

BARBARA, L.; MACÊDO, C.M.M. de. (2011). Processos verbais em artigos acadêmicos: padrões de realização da mensagem. In: BARBARA, Li MOYANO, E. (orgs.) Textos e Linguagem Acadêmica. Campinas, SP: Mercado de Letras. (pp.213-231).

BAZERMAN, C. (1988). Shaping written knowledge. Madison: The University of Wisconsin Press.

BAZERMAN, C.; PRIOR, P. (eds.). (2004). What writing does and how it does it: an introduction to analyzing texts and textual practices. New Jersey: Lawrence Erlbaum Associates. (pp.57-82)

BORGES, M.C.R.; MOREIRA, F.F. (2004). O percurso da autoria. Revista Linguagem em (Dis) curso, vol. 4, no 2, jan./jun. 2004. Disponível em: <http://www3.unisul.br/paginas/ ensino/pos/linguagem/0402/10.htm > Acesso em: 29.abr.2011.

BOTELHO, F.G. (2009). Linguagem acadêmica escrita: um estudo da apropriação das habilidades textuais por alunos do CEFET-MT. Comunicação Oral. Disponível em: 
<http://www.ie.ufmt.br/semiedu2009/gts/gt16/ComunicacaoOral/FLAVIA\%20 GIRARDO\%20BOTELHO.pdf> Acesso em: 11.nov.2011.

BRAIT, B. (1997/2001). Bakhtin e a natureza constitutivamente dialógica da linguagem. In: BRAIT, B. (Org.) Bakbtin, dialogismo e construção de sentido. Campinas, SP: UNICAMP. (pp.91-102)

EGGINS, S.; SLADE, D. (1997). Analysing casual conversation. London: Cassel.

FIGUEIREDO, D. de C.; BONINI, A. (2006). Práticas discursivas e ensino do texto acadêmico: concepções de alunos de mestrado sobre a escrita. Linguagem em (Dis)curso. LemD, Tubarão, v.6, nº 3, p.413-446, set./dez. 2006.

HALLIDAY, M. (1985). An Introduction to Functional Grammar. London: Edward Arnold. (1994). An Introduction to Functional Grammar. London: Edward Arnold.

HALLIDAY, M.; MATTHIESSEN, C. (2004). An Introduction to Functional Grammar. London: Edward Arnold.

HENDGES, G.R. (2002). Citando na Internet: um estudo de gênero da revisão da literatura em artigos acadêmicos eletrônicos. In: MEURER, J.L.; MOTTA-ROTH, D. (orgs.) Gêneros textuais. Bauru, SP: EDUSC. (pp.117-139)

HOOD, S. (2004). Appraising Research: taking a stance in academic writing. Thesis (Doctor of Philosophy) Sydney: Caculty of Education University of Technology.

(2010). Appraising Researcb: evaluation in academic writing. London: Palgrave Macmillan.

MACHADO, A.R.; ABREU-TARDELLI, L.S.; LOUSADA, E. (2005). Planejar gêneros acadêmicos. São Paulo: Parábola Editorial. (Leitura e Produção de Textos Técnicos e Acadêmicos; 3)

MACHADO, A.M.N. (2002). A relação entre a autoria e a orientação no processo de elaboração de teses e dissertações. In: BIANCHETTI, L.; MACHADO, A.M.N. (orgs.). A bússola do escrever: desafios e estratégias na orientação de teses e dissertações. Florianópolis: UFSC; São Paulo: Cortez. (pp.25-37)

MARTIN, J. (1993). Literacy in science: learning to handle text as technology. In: HALLIDAY, M.; MARTIN, J. (eds.). Writing science: literacy and discursive power. London: The Falmer Press.

(2000). Beyond Exchange: appraisal system in English. In: HUNSTON, S.; THOMPSON, G. Evaluation in text: authorial stance and the construction of discourse. Oxford: Oxford University Press.

. (2004). Mourning: how we get aligned. Discourse \& Society, v.15 (2-3), 2004, p.321 244.

MARTIN, J.; ROSE, D. (2003). Working with discourse: meaning beyond the clause. London; New York: Continuum.

MARTIN, J.; WHITE, P. (2005). The language of evaluation: appraisal in English. Londres: Palgrave MacMillan.

MOTTA-ROTH, D. (Org.) (2001). Redação Acadêmica: princípios básicos. $1^{\mathrm{a}}$ ed. Santa Maria: Imprensa Universitária. 
MOTTA-ROTH, D. (2002). A construção social do gênero resenha acadêmica. In: MEURER, J.L.; MOTTA-ROTH, D. (Orgs.) Gêneros Textuais: Subsídios para o ensino da linguagem. Bauru: EDUSC-Editora da Universidade do Sagrado Coração. (pp.66-117)

. (2006). O ensino de produção textual com base em atividades sociais e gêneros textuais. Linguagem em (Dis)curso. LemD, Tubarão, v.6, n.3, p.495-517, set./dez. 2006. . (2007) Escrevendo no contexto: contribuições da LSF para o ensino de redação

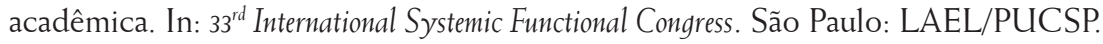

MOTTA-ROTH, D.; HENDGES, G.R. (orgs.) (2010). Produção textual na universidade. São Paulo: Parábola Editorial. (Estratégias de Ensino; 20)

MOTTA-ROTH, D.; LOVATO, C. dos S. (2011). O poder hegemônico da ciência no discurso de popularização científica. Calidoscópio, Vol.2, No 3, p.251-268, set./dez. 2011.

NEVES, M.H. de M. (2000). Gramática de Usos do Português. 6a reimpres. São Paulo: UNESP.

OLIVEIRA, J. M. de. (2008). Ciência e divulgação científica: reflexões sobre o processo de produção e socialização do saber. DOI: 10.2436.20.3008.02.9. Periodística, $n^{\circ} 11$, p.111-124, 2008. Disponível em: <http://www.raco.cat/índex.php/Periodistica/ article/viewFile/245701/328976> Acesso em: 11.nov.2011.

PEDROSA, C.E.F.; MATOS, C.S.S.; MELO, S.P.de A. (2008). Trabalho acadêmico: espaço discursivo de polifonização ou monofonização? SOLETRAS, Ano VIII, nº 15. São Gonçalo: UERJ, jan./jun.2008.

SANTOS, A.L. dos; CARMO, C.M. (2011). A construção do discurso científicoacadêmico por meio do posicionamento dialógico e da gradabilidade dos valores de engajamento: uma abordagem sistêmico-funcional à luz da teoria da avaliatividade. Anais do SILEL. V.2, № 2. Uberlândia: EDUFU, 2011. Disponível em: < http://www. ileel.ufu.br/anaisdosilel/pt/arquivos/silel2011/473.pdf $>$ Acesso em: 18.dez.2011.

SCOTT, M. WordSmith Tools versão 5.o. (2009). Software for text analysis. Oxford: Oxford University Press.

SOUZA, L.M.F. de. (2011). A interação de recursos de comprometimento em um texto opinativo. In: VIAN JR., O.; SOUZA, A.A. de; ALMEIDA, F.S.D.P.. (orgs.) Estudos sistêmico-funcionais com base no Sistema de Avaliatividade. São Carlos: Pedro \& João Editores. (pp. 57-78)

SWALES, J. (1990). Genre analysis: English in academic and research settings. Cambridge: Cambridge University Press.

VIAN JR., O. (2011). Engajamento: monoglossia e heteroglossia. In: VIAN JR., O; SOUZA, A.A. de; ALMEIDA, F.S.D.P. (orgs.) Estudos sistêmico-funcionais com base no Sistema de Avaliatividade. São Carlos: Pedro \& João Editores. (pp.33-40)

WHITE, P. (2002/2004). Valoração - a linguagem da avaliação e da perspective. Trad. Débora de C.Figueiredo. Linguagem em (Dis)curso. LemD, Tubarão, v.4, n.esp., p.177$205,2002 / 2004$. 
WHITE, P. (2003). Beyond modality and hedging: a dialogic view of the language of intersubjective stance. In: MACKEN-HORARIK, M.; MARTIN, J.R. Negotiating beteroglossia: social perspectives on evaluation. Text, v.23 (2), p.259-284, 2003.

. (2011). Engagement: notes and miscellaneous. Workshop on Engagement. Lisbon: $38^{\text {th }}$ International Systemic-Functional Congress, University of Lisbon, jul.2011.

Recebido: $21 / 02 / 2013$

Aceito: 27/04/2013 